\title{
Successful determination of imatinib dosage by therapeutic drug monitoring in a case of chronic myeloid leukemia initiating dialysis for acute renal dysfunction.
}

\author{
Ryosuke Nakahara ${ }^{1}$, Takahiro Sumimoto ${ }^{1}$, Ryota Tanaka ${ }^{1}$, Masao Ogata $^{1}$, and Hiroki Itoh ${ }^{1}$ \\ ${ }^{1}$ Oita University Hospital
}

January 17, 2021

\begin{abstract}
Imatinib is used as first-line treatment for chronic myeloid leukemia (CML) even in patients with impaired renal function. We successfully used therapeutic drug monitoring to determine the dose for re-administration of imatinib in a CML patient who initiated dialysis for acute renal dysfunction associated with the initial imatinib therapy.
\end{abstract}

\section{Successful determination of imatinib dosage by therapeutic drug monitoring in a case of chronic myeloid leukemia initiating dialysis for acute renal dysfunction.}

Ryosuke Nakahara ${ }^{1}$, Takahiro Sumimoto ${ }^{1}$, Ryota Tanaka ${ }^{1}$, Masao Ogata ${ }^{2}$, Hiroki Itoh $^{1}$

${ }^{1}$ Department of Clinical Pharmacy, Oita University Hospital, Yufu-shi, Oita, Japan

${ }^{2}$ Department of Hematology, Oita University Hospital, Yufu-shi, Oita, Japan

\section{Correspondence}

Ryosuke Nakahara, Department of Clinical Pharmacy, Oita University Hospital, Yufu-shi, Oita, Japan. E-mail:ryosuke-n@oita-u.ac.jp

\section{Abstract}

Imatinib is used as first-line treatment for chronic myeloid leukemia (CML) even in patients with impaired renal function. We successfully used therapeutic drug monitoring to determine the dose for re-administration of imatinib in a CML patient who initiated dialysis for acute renal dysfunction associated with the initial imatinib therapy.

\section{Key Clinical Message}

Fixed dose regimen is currently the standard administration method for TKI. However, this case report indicated that TDM may by a useful approach to individualized dosing of TKI for the treatment of CML when initiating dialysis.

\section{Keywords}

Imatinib, chronic myeloid leukemia, dialysis, acute renal dysfunction, therapeutic drug monitoring.

\section{Introduction}

Imatinib is a first generation BCR-ABL tyrosine kinase inhibitor (TKI) with anti-leukemic activity against chronic myeloid leukemia (CML). In the International Randomized Study of Interferon and STI571 (IRIS), 
imatinib was superior to a combination of recombinant interferon alpha (IFN $\alpha$ ) and low-dose cytarabine with respect to the rates of cytogenetic and molecular responses ${ }^{1}$ as well as progression-free survival (PFS) and overall survival. ${ }^{2}$ Given these clinical benefits, imatinib became the first-line treatment for CML. Furthermore, randomized phase 3 trials have revealed that nilotinib and dasatinib, second-generation BCR-ABL TKIs, have superior efficacy compared with imatinib as first-line treatment for chronic myelogenous leukemia in the chronic phase. ${ }^{3,4}$ However, long-term observation of 5 years revealed higher frequency of neovascular adverse effects associated with second-generation TKIs than with imatinib. ${ }^{5,6}$ From the adverse effect profile of the three TKIs, imatinib may be selected as first-line treatment, taking into account patient background such as comorbid diseases. According to a Japanese package insert, typical adverse events of imatinib mesylate include nausea, vomiting, edema, tumor necrosis, muscle cramps, hematologic adverse effects, cardiovascular adverse effects, hepatic adverse effects, nephrotoxicity, and dermatologic adverse effects such as skin rash, pruritus, and petechiae. Initially, renal failure associated with imatinib was reported to be a rare event, occurring in less than $1.0 \%$ of the patients in the dose-escalating studies of chronic phase and blast crisis CML. ${ }^{7,8}$ Similarly, the Novartis Oncology Medical information website (www.oncologymedicalservices.com) reported renal function abnormalities in $1.6 \%$ of $1234 \mathrm{CML}$ patients. However, there were no reports of renal failure among the 553 newly diagnosed CML patients treated with imatinib in the IRIS trial, with follow-up up to 6 years. It is now clear that imatinib therapy is occasionally associated with potentially irreversible acute renal injury, and long-term treatment may cause a clinically significant decrease in estimated glomerular filtration rate. In 105 patients receiving imatinib after prior interferon therapy, $7.0 \%$ developed acute kidney injury with mean decrease in glomerular filtration rate of $2.77 \mathrm{ml} / \mathrm{min}$ per $1.73 \mathrm{~m}^{2}$ per year, and $12 \%$ of patients developed chronic renal failure. ${ }^{9}$ In other cases, renal failure linked to imatinib is often reversible, ${ }^{10,11}$ although hemodialysis is sometimes needed. ${ }^{12}$ Thrombotic thrombocytopenic purpura, ${ }^{13}$ acute tubular necrosis, ${ }^{12}$ tubular vacuolization ${ }^{14}$ and partial Fanconi syndrome ${ }^{15}$ have been reported following imatinib therapy. At the onset of renal disorder or initiation of dialysis, treatment withdrawal or dose reduction of imatinib is required, but there are currently no guidelines for dose adjustment. This report describes a case in which the dose of re-administration of imatinib was successfully determined by therapeutic drug monitoring (TDM) in a patient with CML who initiated dialysis for acute renal dysfunction associated with the initial imatinib therapy.

\section{Case Presentation}

An 88-year-old man treated with imatinib for CML was admitted to our hospital because of dyspnea and malaise. His current medical history was congestive heart failure, hypertension, type 2 diabetes, and chronic kidney disease G5A3. The patient underwent left nephrectomy for left renal cancer in November 2010. At discharge, decreased renal function was observed with blood urea nitrogen (BUN) $23 \mathrm{mg} / \mathrm{dL}$ and creatinine (Cr) $1.5 \mathrm{mg} / \mathrm{dL}$. He was then regularly followed by his family doctor. In February 2014, a routine follow-up blood test revealed white blood cell (WBC) count of $32.6 \times 10^{3} / \mu \mathrm{L}$, and he was referred to our hematology department in March 2014. At that time, renal function deterioration was recognized, with BUN $46 \mathrm{mg} / \mathrm{dL}$ and $\operatorname{Cr} 4.7 \mathrm{mg} / \mathrm{dL}$, and he was clinically diagnosed with chronic phase Philadelphia-positive CML, which was later confirmed by blood tests, bone marrow examination, and imaging findings. In April of the same year, imatinib was started at a dose of $100 \mathrm{mg}$. After 3 weeks, the dose was increased to $200 \mathrm{mg}$. Blood test during outpatient visits showed gradual deterioration of renal function, and he was scheduled to consult a nephrology department. In May of the same year, he complained of dyspnea and malaise and consulted his family doctor. However, he was unable to go the local hospital because of poor physical condition, and was transported to the emergency department of our hospital and was admitted. On the day of admission (day 1), BUN was $54 \mathrm{mg} / \mathrm{dL}$ and $\mathrm{Cr}$ was $5.1 \mathrm{mg} / \mathrm{dL}$, indicating impaired renal function. A plain chest radiograph suggested pulmonary edema. Therefore, he was admitted to the Department of Nephrology of our hospital for initiation of dialysis and treatment of respiratory failure. Imatinib was suspected to have caused the rapid decline in renal function, and administration was discontinued on the same day. He had dyspnea and was poorly oxygenated; $\mathrm{SpO}_{2}$ was $90 \%$ with oxygen administration at $10 \mathrm{~L} / \mathrm{min}$. Pleural effusion and pulmonary edema observed on chest radiograph were considered to be flooding due to exacerbation of chronic renal failure. A flexible double-lumen (FDL) catheter was inserted through the right internal jugular vein and 
emergency dialysis was started. Blood pressure at admission was as high as 182/98 $\mathrm{mmHg}$, and nitroglycerin was administered at $2 \mathrm{~mL} / \mathrm{h}$ and human atrial natriuretic peptide (hANP) at $0.75 \mathrm{~mL} / \mathrm{h}$. Respiratory distress gradually improved with administration of nitroglycerin and hANP, and water removal by dialysis. On day $7,2 \mathrm{~L} /$ min of oxygen delivered via nasal cannula improved $\mathrm{SpO}_{2}$ to $98 \%$, and administration of nitroglycerin and hANP was terminated. The patient was taking $5 \mathrm{mg}$ of oral amlodipine at admission, and the dose was increased to $10 \mathrm{mg}$ due to high blood pressure, and returned to $5 \mathrm{mg}$ when blood pressure decreased by water removal. On day $8, \mathrm{SpO}_{2}$ was maintained at $98 \%$ without oxygen administration, and oxygen therapy was terminated on the same day. Chronic changes in the kidney were observed based on the increase of Cr before admission and CT findings at admission, and maintenance dialysis was considered necessary in the future. Therefore, on day 10, a shunt was built in the left forearm, and maintenance dialysis became possible. After dialysis was initiated, a hematologist re-administered oral imatinib on day 10. A nephrologist consulted us regarding dosage regiment of imatinib and removal rate of imatinib by dialysis in patients with chronic kidney disease. Our search found no clear guidelines regarding the dose of imatinib for dialysis patients. Since imatinib is metabolized in the liver, and $67 \%$ is excreted in feces and 13\% in urine, dosage reduction is not recommended even in patients with renal failure. However, several reports indicated that the same dose for patients with normal renal function is used in patients with renal failure, and that adverse effects were severe in dialysis patients due to high blood imatinib concentration, necessitating dose reduction. ${ }^{16}$ Therefore, we suspected that the blood concentration of imatinib was increased to some extent in this patient. We proposed to measure the plasma concentration of imatinib to examine the imatinib removal rate by dialysis. The dose used to start re-administration was $200 \mathrm{mg} /$ day, the same as that before treatment suspension. At the time of TDM (day 10), WBC was $27.1 \times 10^{3} / \mu \mathrm{L}$, PLT was $423 \times 10^{3} / \mu \mathrm{L}$, BUN was $40.7 \mathrm{mg} / \mathrm{dL}$, and Cr was 5.0 $\mathrm{mg} / \mathrm{dL}$. Plasma concentration was determined by a high performance liquid chromatographic method as described previously. ${ }^{17}$ Using this method, the plasma concentration of imatinib was $1667 \mathrm{ng} / \mathrm{mL}$ (Figure 1) at the $8^{\text {th }}$ day of re-administration. This value was higher than the mean trough concentration of $1002 \mathrm{ng} / \mathrm{mL}$ reported to be effective in treating CML by Picard et al. ${ }^{18}$ After confirming the TDM results, the attending physician decided to continue prescribing the same dose. After resuming imatinib, WBC counts declined markedly to $14.65 \times 10^{3} / \mu \mathrm{L}$ on day 20 . On day 37 (27 days after resuming administration), steady-state blood concentration was confirmed. The trough plasma concentration of imatinib was $2514 \mathrm{ng} / \mathrm{mL}$ (Figure 1). This value was lower than the mean trough concentration of $3180 \mathrm{ng} / \mathrm{mL}$ reported to be associated with a higher frequency of grade $3 / 4$ adverse events such as neutropenia. ${ }^{19}$ Renal function did not exacerbate, and no other adverse events were observed. At that time, WBC was $10.24 \times 10^{3} / \mu \mathrm{L}$, PLT was $155 \times 10^{3} / \mu \mathrm{L}$, BUN was $48.0 \mathrm{mg} / \mathrm{dL}$, and $\mathrm{Cr}$ was $6.0 \mathrm{mg} / \mathrm{dL}$. After confirming the TDM results and no adverse events, the attending physician decided to continue prescribing the same dose. On day 44, complete hematologic response (CHR) was achieved with normalization of peripheral blood data and extramedullary lesions. CHR was achieved within 3 months after the start of treatment, corresponding to the criteria of optimal response to TKI treatment. ${ }^{20}$ On day 49 , the patient's condition was stable with dialysis and imatinib therapy, and he was transferred to another hospital.

\section{Discussion}

Imatinib is a first generation BCR-ABL TKI, and has anti-leukemic activity against CML. Treatment of CML has improved dramatically with the development of TKIs, including imatinib. However, the inter-individual variability in adverse events and clinical efficacy as well as high drug cost remain major issues, and present a major obstacle to treatment. There is also an issue of reduced efficacy and safety with prolonged TKI administration. Therefore, TDM of TKIs is an important tool for CML treatment. We have previously reported a case report of successful determination of nilotinib dosage by TDM in a patient with CML developing hepatic dysfunction. ${ }^{21}$ The safety and efficacy of imatinib for CML have been reviewed. ${ }^{22}$ Maintaining an optimal trough plasma imatinib concentration is important for ensuring maximum efficacy in patients with CML. ${ }^{22}$ However, there is few case reports of effective dose adjustment of imatinib using TDM at the onset of adverse events. As one of the few case reports, Shibuya et al., when imatinib was administered at $400 \mathrm{mg} /$ day to CML associated with maintenance dialysis patients, the $\mathrm{C}_{\max }$ was $2,600 \pm 800 \mathrm{ng} / \mathrm{mL}$ in normal subjects, ${ }^{23}$ but $4,950 \mathrm{ng} / \mathrm{mL}$ in dialysis patients was calculated. ${ }^{16}$ In addition, the imatinib removal 
rate by dialysis was as low as $6.3 \%$, and it has been reported that blood imatinib concentration increases gradually with continued administration in dialysis patients and may reach a peak of $5,800 \mathrm{ng} / \mathrm{mL}$, which is considered to be the toxic level of imatinib. ${ }^{16}$ Furthermore, imatinib is metabolized in the liver by cytochrome P450 3A4 (CYP3A4). Since there are reports that uremic substances can reduce CYP3A4 activity in patients with chronic renal failure, caution should be exercised in long-term use of drugs that are metabolized in the liver. ${ }^{24,25}$ In this case, approximately one week after resuming imatinib when dialysis was initiated for renal impairment, TDM revealed that imatinib plasma level was within the therapeutic range (1667 ng/mL). TDM performed one month after imatinib was resumed with the patient on dialysis showed blood imatinib concentration of $2514 \mathrm{ng} / \mathrm{mL}$, which was within the safe range. These results also support previous report that the target trough concentration of imatinib is $1000-3000 \mathrm{ng} / \mathrm{mL} .{ }^{22}$ After blood imatinib concentration was confirmed by TDM, the physician decided to continue with the same dose. Treatment was continued without any adverse effects such as deterioration of renal function, and finally complete hematologic response was achieved 43 days after resuming imatinib treatment. Thus, TDM allowed maintenance of optimal plasma imatinib concentrations, which not only prevented the occurrence of adverse events, but also maintained clinical efficacy. This case report demonstrates successful determination of imatinib dosage by TDM in a CML patient at initiation of dialysis for acute renal dysfunction. TDM may provide useful marker for individualized dosing of BCR-ABL TKIs in the treatment of CML.

\section{Authorship}

RN: analyzed data and wrote the manuscript. TS: analyzed data. MO: managed the patient. RT: wrote the manuscript and reviewed the manuscript, and HI: reviewed the manuscript. All authors read and approved the manuscript to be submitted.

\section{Conflict of Interest}

There are no conflicts of interest to report.

\section{Patient consent}

Written informed consent was obtained from the patient for publication of this case report and accompanying clinical data.

\section{Acknowledgment}

No funding source had involvement in the design, analysis, or writing of this manuscript.

\section{References}

1. O'Brien SG, Guilhot F, Larson RA, Gathmann I, Baccarani M, Cervantes F, et al. (2003) Imatinib compared with interferon and lowdose cytarabine for newly diagnosed chronic-phase chronic myeloid leukemia. N Engl J Med 348:994-1004

2. Hochhaus A, Larson RA, Guilhot F, Radich JP, Branford S, Hughes TP, et al. (2017) Long-term outcomes of imatinib treatment for chronic myeloid leukemia. N Engl J Med 376:917-27

3. Saglio G, Kim DW, Issaragrisil S et al (2010) Nilotinib versus imatinib for newly diagnosed chronic myeloid leukemia. New Engl J Med 362:2251-2259

4. Kantarjian H, Shah NP, Hochhaus A et al (2010) Dasatinib versus imatinib in newly diagnosed chronicphase chronic myeloid leukemia. New Engl J Med 362:2260-2270

5. Hochhaus A, et al. (2016) Long-term benefits and risks of frontline nilotinib vs imatinib for chronic myeloid leukemia in chronic phase : 5-year update of the randomized ENESTnd trial. Leukemia 30(5):1044-54

6. Cortes JE, et al. (2016) Final 5-year study results of DASISION : The dasatinib versus imatinib study in treatment-naive chronic myeloid leukemia patients trial. J Clin Oncol 34(20):2333-40

7. Druker BJ, Sawyers CL, Kantarjian H, Resta DJ, Reese SF, Ford JM et al. (2001) Activity of a specific inhibitor of the BCR-ABL tyrosine kinase in the blast crisis of chronic myeloid leukemia and acute lymphoblastic leukemia with the Philadelphia chromosome. N Engl J Med 344:1038-1042 
8. Druker BJ, Talpaz M, Resta DJ, Peng B, Buchdunger E, Ford JM et al. (2001) Efficacy and safety of a specific inhibitor of the BCR-ABL tyrosine kinase in chronic myeloid leukemia. N Engl J Med 344: 1031-1037

9. Marcolino MS, Boersma E, Clementino NC, Macedo AV, Marx-Neto AD, Silva MH, et al. (2011) Imatinib treatment duration is related to decreased estimated glomerular filtration rate in chronic myeloid leukemia patients. Ann Oncol 22:2073-2079

10. Kitiyakara C, Atichartakarn V. (2002) Renal failure associated with a specific inhibitor of BCR-ABL tyrosine kinase, STI 571. Nephrol Dial Transplant 17:685-687

11. Gafter-Gvili A, Ram R, Gafter U, Shpilberg O, Raanani P. (2010) Renal failure associated with tyrosine kinase inhibitors - case report and review of the literature. Leuk Res 34:123-127

12. Pou M, Saval N, Vera M, Saurina A, Sole M, Cervantes F, et al. (2003) Acute renal failure secondary to imatinib mesylate treatment in chronic myeloid leukemia. Leuk Lymphoma 44:1239-1241

13. Al Aly Z, Philoctete Ashley JM, Gellens ME, Gonzalez EA. (2005) Thrombotic thrombocytopenic purpura in a patient treated with imatinib mesylate: true association or mere coincidence? Am J Kidney Dis 45:762-768

14. Foringer JR, Verani RR, Tjia VM, Finkel KW, Samuels JA, Guntupalli JS. (2005) Acute renal failure secondary to imatinib mesylate treatment in prostate cancer. Ann Pharmacother 39:2136-2138

15. Francois H, Coppo P, Hayman JP, Fouqueray B, Mougenot B, Ronco P. (2008) Partial fanconi syndrome induced by imatinib therapy: a novel cause of urinary phosphate loss. Am J Kidney Dis 51:298-301

16. Shibuya Y, Matsuo K, Kosugi T, Gomi T. (2004) Pharmacokinetics and side effects of imatinib mesilate $\left(\right.$ Glivec $\left.^{(\mathrm{r})}\right)$ in a hemodialysis patient with chronic myeloid leukemia. Journal of Japanese Society for Dialysis Therapy 37:239-42

17. Nakahara R, Sato Y, Itoh H. (2016) High-performance liquid chromatographic ultraviolet detection of nilotinib in human plasma from patients with chronic myeloid leukemia, and comparison with liquid chromatography-tandem mass spectrometry. J Clin Lab Anal. 30,1028-1030

18. Picard S, Titier K, Etienne G, Teilhet E, Ducint D, Bernard MA, Lassalle R, Marit G, Reiffers J, Begaud B, Moore N, Molimard M, Mahon FX. (2007) Trough imatinib plasma levels are associated with both cytogenetic and molecular responses to standard-dose imatinib in chronic myeloid leukemia. Blood, 109, 3496-3499

19. Guilhot F, Hughes TP, Cortes J, Druker BJ, Baccarani M, Gathmann I, Hayes M, Granvil C, Wang Y. (2012) Plasma exposure of imatinib and its correlation with clinical response in the Tyrosine Kinase Inhibitor Optimization and Selectivity Trial. Haematologica 97(5):731-738

20. Baccarani M, et al. (2013) European Leukemia Net recommendations for the management of chronic myeloid leukemia. Blood 122:872-884

21. Nakahara R, Sumimoto T, Ogata M, Sato Y, Itoh H. (2019) Successful determination of nilotinib dosage by therapeutic drug monitoring in a patient with chronic myeloid leukemia developing hepatic dysfunction: A case report. Clin Case Rep., 7:1419-1421

22. Miura M. (2015) Therapeutic drug monitoring of imatinib, nilotinib, and dasatinib for patients with chronic myeloid leukemia. Biol Pharm Bull. 38(5):645-654

23. Peng B, Lloyd P, Schran H. (2005) Clinical pharmacokinetics of imatinib. Clin Pharmacokinet 44:87994

24. Ladda MA, Goralski KB. (2016) The Effects of CKD on cytochorome P450-medeiated drug metabolism. Adv Chronic Kidney Dis 23:67-75

25. Uchida N, Kurata N, Shimada K, et al. (1995) Changes of hepatic microsomal oxidative drug metabolizing enzymes in chronic renal failure (eCRF) rats by partial nephrectomy. Jpn J Pharmacol 68:431-9

\section{Hosted file}

image1.emf available at https://authorea.com/users/390007/articles/504468-successfuldetermination-of-imatinib-dosage-by-therapeutic-drug-monitoring-in-a-case-of-chronicmyeloid-leukemia-initiating-dialysis-for-acute-renal-dysfunction 
Figure 1. Clinical course. After onset of renal disorder and initiation of dialysis, TDM revealed that plasma imatinib level was within the therapeutic range. Thereafter, white blood cell count decreased to baseline level $\left(3.3-8.6 \times 10^{3} / \mu \mathrm{L}\right)$, then reached complete hematologic response. TDM, therapeutic drug monitoring; $\mathrm{C}_{0}$, trough concentration; CHR, complete hematologic response; WBC, white blood cell count; PLT, platelet; $\mathrm{X}$ axis on the left represents WBC count $\left(\times 10^{3} / \mu \mathrm{L}\right)$ and creatinine levels $(\mathrm{mg} / \mathrm{dL})$. $\mathrm{Y}$ axis on the right represents PLT count $\left(\times 10^{3} / \mu \mathrm{L}\right)$. 